\title{
Pierre-Charles-Alexandre Louis and the evaluation of bloodletting
}

\author{
Alfredo Morabia
}

J R Soc Med 2006;99:158-160

Additional material for this article is available from The James Lind Library website [www.jameslindlibrary.org] where this paper was previously published.

\section{THE BLOODLETTING CONTROVERSY}

In the early 1800s, medicine in Europe had to deal with all kinds of 'fevers'. Fever was not necessarily considered as a symptom of specific disorders; fevers could be disease categories by themselves. Examples include septic fever following amputations; puerperal, choleric, yellow, slow continuous, hectic, and diarrhoeic fevers; not to mention hepatitis, pneumonitis and ophthalmia. ${ }^{1}$

In the aftermath of the French Revolution, François Joseph Victor Broussais (1772-1838), a Parisian doctor and a Jacobin, claimed that all fevers had the same origin: they were manifestations of the inflammation of organs. Accordingly, leeches were applied on the surface of the body corresponding to the inflamed organ and the resultant bloodletting was deemed to be an efficient treatment. For example, the chest of a patient suspected of having pneumonitis was covered with a multitude of leeches. Broussais's theories were highly regarded by contemporary French physicians. His influence can be assessed using an economic measure: in 1833 alone, France imported 42 million leeches for medical use. ${ }^{2}$ ( $\mathrm{p}$ 62)

Before he began practising in France, Pierre-CharlesAlexandre Louis (1787-1872) had had some experience as a clinician in Russia. He doubted of the validity of Broussais' theory and published several monographs arguing against it. The most relevant of these-'Research on the effects of bloodletting in some inflammatory diseases' - appeared first as an article in the Annales de Médecine Générale in $1828 .^{3}$ The paper was revised and amplified and published as a book in $1835,{ }^{4}$ and this was translated and published in English in the USA the following year. ${ }^{5}$

Louis was a meticulous clinician and this had important implications for the quality of his research. He had a large collection of case records, which he had assembled during years of intensive clinical activity and autopsy in the Parisian hospital La Charité. The 77 patients that he selected for his bloodletting analysis were a very homogeneous group with the same, well-characterized form of 'pneumonia'. They had all been in perfect health at the time of the first symptoms of their disease Morabia and Rochat. ${ }^{6}$ found complete agreement with Louis's definition of pneumonia among 43 contemporary chest physicians presented with Louis' description of a case of 'pneumonia'.

After establishing as accurately as he could the timing of the onset of the disease in each patient, Louis analysed the duration of the disease and the frequency of death by the timing of the first bloodletting. He grouped patients by whether they had been bled early (days 1-4 of the illness) or late (days 5-9). This division resulted in two comparison groups of 41 and 36 patients, which were of comparable average age (41 and 38 years, respectively). But Louis also wrote that:

'it is nevertheless true, that the number of patients bled on the first day, who had passed the age of fifty, was nearly twice as great as that of the patients of the same age, who were bled at a later period. This must have had great influence on mortality' 5 (p. 10)

What did Louis find when he compared the evolution of the disease among the two groups of carefully selected patients he had assembled? He found that the duration of disease was an average of 3 days shorter in those who had been bled early compared with those who had been bled late. However, 'three sevenths' (i.e., $44 \%$ ) of the patients who had been bled early died compared to 'only one fourth' (i.e., $25 \%$ ) of those bled late, a result that Louis remarked was 'startling and apparently absurd'. ${ }^{5}$ (p. 9)

Louis was aware of the possibility that patients bled later in the course of the disease had already passed the worst phase of their illness, and that they might therefore have had a better prognosis. Recognizing that this bias would have favoured late bleeding, he made careful comparisons of the severity of symptoms among those bled early and those bled late, but he was unable to detect any differences. ${ }^{5}$ (pp. 13-14)

In the light of these findings, Louis concluded that there were useful effects of bloodletting, but only for specific indications:

'Thus, the study of the general and local symptoms, the mortality and variations in the mean duration of 
pneumonitis, according to the period at which bloodletting was instituted; all establish narrow limits to the utility of this mode of treatment. ${ }^{5}$ ( p. 13)

In his view, the validity of this treatment was limited to severe cases of disease:

'I will add that bloodletting, notwithstanding its influence is limited, should not be neglected in inflammations which are severe and are seated in an important organ; both on account of its influence on the state of the diseased organ; and because in shortening the duration of the disease, it diminishes the chance of secondary lesions'.$^{5}$ (p. 23)

Louis also believed, without providing supporting quantitative evidence, that abundant bleeding worked better than local bleeding:

'These observations seem to show that the use of the lancet should be preferred to that of leeches in the diseases which we have been considering' ${ }^{5}$ (p. 23)

The impact of Louis's analysis on the practice of medicine is hard to assess. Broussais's theories had already lost support by the time that Louis' book was published, ${ }^{2}$ (p. 67).

\section{WAS LOUIS A CLINICAL EPIDEMIOLOGY PIONEER?}

Even though there was no formalized theory of epidemiology in the first half of the 19th century, Louis was what we could call today a 'pre-formal' epidemiologist because he based his 'recherches' on epidemiology's two principles: group comparison and population thinking. ${ }^{8}$

\section{Group comparisons}

Louis compared groups and understood that these had to be similar in all aspects other than treatment.

'What was to be done in order to know whether bloodletting had any favorable influence on pneumonitis, and the extent of that influence? Evidently to ascertain whether, other things being equal, the patients who were bled on the first, second, third or fourth day of their illness, recovered more readily than those bled at a later period. In the same manner, it was necessary to estimate the influence of age, or, more generally, any other circumstance, on the appreciable effects of bloodletting'4 (pp. 70-71) ${ }^{5}$ (p. 55) [my emphases]
'For example, in any particular epidemic, let us suppose five hundred of the sick, taken indiscriminately, are subjected to one kind of treatment, and five hundred others, taken in the same manner, are treated in a different mode; if the mortality is greater among the first than among the second, must we not conclude that the treatment was less appropriate, or less efficacious in the first class than in the second? It is unavoidable; for among so large a collection, similarities of conditions will necessarily be met with, and all things being equal, the conclusion will be rigorous.' ${ }^{4}$ (pp. 75-76) ${ }^{5}$ (pp. 59-60) [my emphases]

In the first of these passages, Louis formulates the central issue of group comparability as 'other things being equal' and as the necessity to take into account other determinants of recovery, which might be unequally distributed in the groups (age, for example) and therefore 'influence' the apparent 'effects' of bloodletting. In another section of the book, Louis mentions 'causes which, independently of the period of the first bleeding, must have effected some difference in the mean duration of the disease'. ${ }^{5}$ (p. 6) These include diet before bleeding, age, severity of symptoms at the beginning of the disease and treatments other than bloodletting.

These same notions are expressed in the second passage. Louis mentions taking the patients 'indiscriminately', assembling the two groups in which treatment will be compared 'in the same manner', and goes on to emphasize again 'all things being equal'. This passage even indicates that Louis suspected the potential benefit of what we would call now random allocation of treatment on the comparability of the groups.

\section{Population thinking}

Louis also thought in terms of population when he explained that predictions could only be made with a measurable degree of certainty at the group but not at the individual level.

'Let us further remark that the objection made to the numerical method, to wit, the difficulty or impossibility of forming classes of similar facts, is alike applicable to all the methods that might be substituted. It is impossible to appreciate each case with mathematical exactness, and it is precisely on this account that enumeration becomes necessary. By so doing, the errors (which are inevitable) being the same in the two groups of patients subjected to different treatments, mutually compensate each other, and they may be disregarded without materially affecting the exactness of the results'.$^{4}$ (pp 75-76) ${ }^{5}$ (pp 59-60) [my emphases] 
The impossibility of assessing the efficacy of treatment in single patients is consistent with the fact that Louis was not expecting an all-or-none response to treatment but a probabilistic difference. In the passage above, Louis explained that that for bloodletting to be appropriate or effective in the treatment of pneumonia, mortality has to be 'greater' in the group bled early than among patients bled later.

Louis was on less secure ground in suggesting that errors could be disregarded in comparisons between the two groups because they would 'mutually compensate each other'. This view would only have been confidently justified for selection biases if his comparison groups had been generated using random allocation. They would not apply in respect of errors related to the classification of exposure or outcome.

\section{TEACHING MATERIAL}

We have compiled the data reported by Louis in the English version of 'Researches on the effects of bloodletting in some inflammatory diseases' 5 _ it can be accessed at [www. epidemiology.ch/history/louis.htm]. Some typographical errors present in the French version have been corrected in the English translation. ${ }^{9}$ You can use Louis' data and reanalyse them, either by comparing the patients who died with those who survived, or those who were bled early (14 days) with those bled late ( $>4$ days). Using the variable 'duration of disease', you can also perform a survival analysis (as published by Morabia in 1996). ${ }^{9}$ Whichever analytical approach is used, the group bled during the first four days of disease does worse $(P$-value $=0.07)$, and this would appear to make a protective effect of bleeding highly unlikely.

\section{CONCLUSION}

Pierre Louis is revered as an important precursor of modern clinical epidemiology in the first half of the 19th century. We know about his existence, and we can read his work. But Louis the man remains essentially an enigma. Louis promoted the 'numerical method', that is, the idea that new and valid medical knowledge could be derived from aggregated clinical data. But where did his interest in quantitative medicine come from? Did he have any mathematical training? Did he study the work of the French mathematicians, and in particular the treatises on probability of Pierre-Simon Laplace (1749-1827)? In addition, whether he was studying the efficacy of bloodletting, or the causes of emphysema or of tuberculosis, Louis cared about the validity of group comparisons and the quality of observations on which they were based, and he checked the logical consistency of his results.

What were the sources of his concern for the theoretical principles of objectivity, reproducibility and comparability, which he systematically and characteristically referred to in his approach to clinical problems? Was Louis aware of the British work on quantification during the 18th and early 19 th centuries recently resurrected by Tröhler? ${ }^{1,7}$ Like the doctors who developed British medical arithmetic, Louis was relatively marginal to the medical academic establishment. This distance gave him freedom to develop original ideas and to challenge Parisian medical authorities like Broussais, in a way that no other doctor of provincial extraction would. As far as I am aware, these questions have not been answered yet, but addressing them may shed new light on a crucial period in the joint evolution of epidemiology and medicine.

\section{REFERENCES}

1 Tröhler U. Quantifying experience and beating biases: A new culture in eighteenth-century British clinical medicine. In: Jorland G, Opinel A, Weisz G, eds. Body Counts. Medical Quantification In Historical And Sociological Perspective. Montreal: McGill-Queens's University Press, 2005:9-50

2 Ackerknecht EH. Medicine at the Paris Hospital, 1794-1848. Baltimore: Johns Hopkins Press, 1967

3 Louis PCA. Recherche sur les effets de la saignée dans plusieurs maladies inflammatoires. Arch Gen Med 1828;21:321-36

4 Louis PCA. Recherches Sur Les Effets De La Saignée Dans Quelques Maladies Inflammatoires Et Sur L'action De L'émétique Et Des Vésicatoires Dans La Pneumonie. Paris: Librairie de l'Académie royale de médecine, 1835

5 Louis PCA. Researches On The Effects Of Bloodletting In Some Inflammatory Diseases. Boston: Hilliard, Gray, 1836

6 Morabia A, Rochat T. Reproducibility of Louis' definition of pneumonia. Lancet 2001;358:1188

7 Tröhler U. 'To Improve The Evidence Of Medicine': The 18th Century British Origins of A Critical Approach. Edinburgh: Royal College of Physicians, 2000

8 Morabia A. Epidemiology: an epistemological perspective. In: Morabia A, ed. History of Epidemiological Methods and Concepts. Basel: Birkhauser, 2004:1-126

9 Morabia A. PCA Louis and the birth of clinical epidemiology. J Clin Epidemiol 1996;49:1327-33 